\title{
Duck enteritis virus activates CaMKK $\beta$ - AMPK to trigger autophagy in duck embryo fibroblast cells via increased cytosolic calcium
}

\author{
Haichang Yin ${ }^{1,2,3+}$, Lili Zhao ${ }^{1 \dagger}$, Yiping Wang ${ }^{1}$, Siqi $\mathrm{Li}^{1}{ }^{1}$ Hong Huo ${ }^{1}$ and Hongyan Chen ${ }^{1 *}$
}

\begin{abstract}
Background: The results of our previous study showed that impaired cellular energy metabolism contributes to duck enteritis virus-induced autophagy via the $5{ }^{\prime}$-adenosine monophosphate-activated protein kinase (AMPK)/ tuberous sclerosis complex 2/mammalian target of rapamycin pathway in duck embryo fibroblast (DEF) cells. However, it remains unknown whether any other underlying mechanisms of AMPK activation are involved in autophagy induction.
\end{abstract}

Methods: The activity of CaMKK $\beta$ and AMPK in DEF cells infected with DEV were evaluated.The Effect of inhibitory activity of CaMKK $\beta$ on DEV-induced autophagy was investigated. In addtion to, the cytosolic calcium level in DEF cells infected with DEV were evaluated.The Effect of inhibitory cytosolic calcium level on DEV-induced autophagy was investigated.

Results: In this study, duck enteritis virus (DEV) infection activated CaMKK $\beta$ and its substrate molecule AMPK at 36, 48, and 60 h post-infection (hpi). STO-609, a CaMKKß inhibitor, or CaMKK $\beta$ siRNA significantly inhibited the activation of DEV to AMPK, LC3I to LC3II transformation, and GFP-LC3 puncta distribution. In addition, inhibition of CaMKK $\beta$ activity also significantly reduced progeny DEV titer and gB protein expression. Besides, cytosolic calcium $\left(\mathrm{Ca}^{2+}\right)$ was higher in DEV-infected cells than mock controls at 36, 48, and 60 hpi, respectively. Treatment of DEV-infected cells with 1,2-Bis (2-aminophenoxy) ethane- $\mathrm{N}, \mathrm{N}, \mathrm{N}$ ', N-tetraacetic acid (BAPTA-AM) significantly reduced intracellular $\mathrm{Ca}^{2+}$ ion concentrations, as well as CaMKK $\beta$ and AMPK activities, and subsequent autophagy, in addition to viral protein synthesis and viral titer.

Conclusions: These results showed that elevated $\left[\mathrm{Ca}^{2+}\right] c y t o-m e d i a t e d$ activation of CaMKK $\beta$ managed the activation of AMPK, which then positively regulated autophagy, thereby providing further insight into DEV-host interactions.

Keywords: Duck enteritis virus, Autophagy, Cytosolic calcium, CaMKKß, AMPK

\section{Background}

Duck enteritis virus (DEV) is a member of the Herpesviridae family and has a typical morphology of herpesviruses and a double-stranded, linear DNA genome about $160 \mathrm{~Kb}$ in length. DEV can cause a variety of acute, septic, and highly fatal infectious diseases in water fowl, including

\footnotetext{
* Correspondence: sydw2014@163.com

${ }^{+}$Haichang Yin and Lili Zhao contributed equally to this work.

${ }^{1}$ State Key Laboratory of Veterinary Biotechnology, Heilongjiang Provincial Key Laboratory of Laboratory Animal and Comparative Medicine, Harbin Veterinary Research Institute, the Chinese Academy of Agriculture Sciences, 678 Haping Road, Harbin 150069, People's Republic of China
}

duck viral enteritis (DVE), which is characterized by internal bleeding due to mucosal damage of the blood vessels and digestive tract, as well as lymphoid organ damage and lesion formation [1]. The occurrence of DVE was first reported in the Netherlands in 1923 and has since spread to other countries. In 1957, the occurrence of the DVE was first reported in China and has since prevailed in relatively developed areas in southern and eastern China [2]. DVE is widespread and spreads rapidly, resulting in high morbidity and mortality that results in huge economic losses to the duck industry. However, the

(C) The Author(s). 2018 Open Access This article is distributed under the terms of the Creative Commons Attribution 4.0 International License (http://creativecommons.org/licenses/by/4.0/), which permits unrestricted use, distribution, and 
relative lag in molecular biology research has restricted efforts in DVE prevention and control.

Virus infection can induce autophagy, which is a process of precise membrane-dependent regulation to ensure intracellular fluid balance [3-5]. This response can be either antiviral or promote virus replication, depending on the type of virus and the intracellular environment of the host cell $[6,7]$. According to the type of substrate, species, regulatory mechanism, and transport process, autophagy includes macroautophagy, microautophagy, and molecular chaperone-mediated autophagy [8]. Macroautophagy commonly refers to the process of double layer membrane formation of autophagosomes by fusion of the endoplasmic reticulum (ER) with lysosomes. In this process, commonly referred to as autophagy, the contents of autophagosomes are degraded.

Calcium $\left(\mathrm{Ca}^{2+}\right)$ is a ubiquitous intracellular messenger of some important signal transduction processes, including activation of enzymes, differentiation, proliferation, and gene transcription $[9,10] . \mathrm{Ca}^{2+}$ and calcium-sensing proteins might play a dual role in the process of autophagy regulation, depending on the cell type, intracellular environment, and $\mathrm{Ca}^{2+}$ abundance $[11,12]$. Excessive cytoplasmic calcium is released from the ER, and then was reported to induce autophagy through calcium/calmodulin-dependent protein kinase kinase-beta (CaMKK) -regulated activation of adenosine 5 '-monophosphate-activated protein kinase (AMPK) and the subsequent inhibition of the activity of mammalian target of rapamycin (mTOR) [13, 14].

Some viruses can take advantage of $\mathrm{Ca}^{2+}$ ion-related pathways of the host to promote replication $[15,16]$, such as porcine circovirus type 2, which can induce the release of $\mathrm{Ca}^{2+}$ ions from the ER via the inositol 1,4,5-trisphosphate receptor in duck embryo fibroblast (DEF) cells, which is considered to be responsible for apoptosis induction [17]. Rotavirus coding of nonstructural protein 4 , which releases $\mathrm{Ca}^{2+}$ ions into the cytoplasm, initiates autophagy to activate CaMKK $\beta$ signaling [18]. The hepatitis $B$ virus $X$ protein targets the human B-cell lymphoma 2 homolog to regulate CED-9, which induces an increase in cytoplasmic $\mathrm{Ca}^{2+}$ ion concentrations and subsequent cell death in Caenorhabditis elegans [19]. Herpes simplex virus triggers activation of calcium-signaling pathways [20], Elevated [Ca2+]cyto-mediated activation of CaMKK $\beta$ exactly managed the activation of AMPK, which then positively regulated autophagy through suppressing mTOR in cells infected with Bluetongue virus [21].

Our previous studies showed that impaired cellular energy metabolism contributes to DEV-induced autophagy via the AMPK/TSC2/mTOR pathway in DEF cells [22, 23]. However, it remains unknown whether other underlying mechanisms of AMPK participate in autophagy induction.
The results of the present study demonstrated that CaMKK $\beta$ is an upstream regulator of AMPK during DEV infection, which contributes to autophagy induction. Activation of CaMKK $\beta$ results from an increase in cytosolic $\mathrm{Ca}^{2+}$ content. This research lays a foundation for DEV pathogenic mechanism research and provides further insight into DEV-host cell interactions.

\section{Methods}

\section{Cells, viruses, and plasmids}

DEF cells were obtained from 9 to 11 days specific pathogen-free duck embryos, as described previously [24], and cultured in Dulbecco's modified Eagle's medium (cat. no. 8116176; Gibco, Grand Island, NY, USA) supplemented with $5 \%$ fetal bovine serum (cat. no. 1722658; Gibco) and antibiotics $(0.1 \mathrm{mg} / \mathrm{ml}$ of streptomycin and $0.1 \mathrm{mg} / \mathrm{ml}$ penicillin) at $37{ }^{\circ} \mathrm{C}$ under an atmosphere of $5 \% \mathrm{CO}_{2} / 95 \%$ air. DEV strain CSC was kept in our laboratory.

To construct a GFP-LC3 recombination plasmid, the LC3 gene was amplified from DEF cells with the primer pair LC3F $5{ }^{`}$-ATG CAA CCG CCT CTG-3` and LC3R 5'-TCG CGT TGG AAG GCA AAT C-3', corresponding to the GenBank sequence for duck LC3B gene (NW_004676873.1), and cloned into the pEGFP-C1 vector, to express LC3B protein with the GFP protein.

\section{Virus infection and drug or small interfering RNA (siRNA) treatment}

DEF cells were infected with DEV for $2 \mathrm{~h}$ at $37^{\circ} \mathrm{C}$, washed three times with sterile phosphate-buffered saline ( $\mathrm{pH}$ 7.4), then maintained in $2 \%$ in culture medium supplemented with fetal bovine serum for various time points until samples were harvested. The cells were then cultured in $2 \%$ culture medium supplemented with fetal bovine serum with or without pre-treatment with the same drug for the indicated times. The optimal concentrations of chemicals used in this experiment were $10 \mathrm{mM}$ 1,2-Bis(2-aminophenoxy)ethane- $\mathrm{N}, \mathrm{N}, \mathrm{N}^{\prime}, \mathrm{N}$-tetraacetic acid (BAPTA-AM; Abcam, Cambridge, UK), $5 \mu \mathrm{M}$ STO-609 (Merck-Millipore, Darmstadt, Germany), $4 \mu \mathrm{M}$ ionomycin and 2.5 $\mu \mathrm{M}$ Fluo-3 AM (Beyotime Institute of Biotechnology, Haimen, China). The toxicities of both drugs and siRNAs were tested using the WST-1 Cell Proliferation and Cytotoxicity Assay Kit (Beyotime), according to the manufacturer's instructions. At 36, 48, and $60 \mathrm{~h}$ post-infection (hpi), DEF cells were collected for subsequent analysis.

\section{Western blot analysis}

Proteins from cells treated with either drugs or siRNAs, or infected with DEV were extracted using immunoprecipitation lysis buffer (Beyotime) with the protease inhibitor phenylmethylsulfonyl fluoride (Beyotime), then boiled for 
10 min in $5 \times$ loading buffer, separated by $12 \%$ sodium dodecyl sulfate-polyacrylamide gel electrophoresis, and transferred onto nitrocellulose membranes (GE Healthcare Life Sciences, Little Chalfont, UK), according to manufacturers' instructions. The membranes were blocked with 3\% bovine serum albumin (Sigma-Aldrich Corporation, St. Louis, MO, USA) for $2 \mathrm{~h}$ at room temperature and then incubated with the following primary antibodies for $2 \mathrm{~h}$ at room temperature: rabbit anti-LC3B antibody (Sigma-Aldrich Corporation), mMouse anti-CaMKK $\beta$ antibody (Sigma-Aldrich Corporation), rabbit anti-p-AMPK antibody (Thermo Fisher Scientific, Waltham, MA, USA), mouse anti-AMPK antibody (Thermo Fisher Scientific), mouse anti- $\beta$-actin antibody (Sigma-Aldrich Corporation).Then, the membranes were incubated with IRDye $800 \mathrm{CW}$ goat anti-mouse or goat anti-rabbit immunoglobulin IgG as secondary antibodies for $1 \mathrm{~h}$ at room temperature. Antibody detection was conducted using an Odyssey Infrared Fluorescence Scanning Imaging System (LI-COR Biosciences, Lincoln, NE, USA). Quantitation from western blot image intensity was achieved by adding rectangle to the image to gain data directly using the Odyssey Infrared Fluorescence Scanning Imaging System Application Software Version3.0.

\section{Confocal fluorescence microscopy}

For the detection of autophagosomes, DEF cells at 70-80\% confluence in culture dishes were transfected with $2.5 \mu \mathrm{g}$ of the GFP-LC3 plasmid using the Calcium Phosphate Transfection Kit (cat. no. K2780-01; Invitrogen Corporation, Carlsbad, CA, USA). At $24 \mathrm{hpi}$, chemical-treated or virus-infected DEF cells at different time points were fixed with absolute ethanol for $30 \mathrm{~min}$ and the cell nuclei were stained with 4'-6-diamidino-2-phenylindole (cat. no. D1306; Beyotime). The green fluorescence of GFP-LC3 was observed by confocal laser microscopy using a Leica SP2 confocal system (Leica Microsystems, Wetzlar, Germany).

\section{CaMKK $\beta$ siRNA}

In order to further study the effects of cell autophagy on viral replication, siRNA targeting the autophagy-related gene beclin-1 was synthesized (Shanghai GenePharma Co., Ltd., Shanghai, China). The sequence of the siRNA was GCC UAC AAC GAG GAC GAU ATT (sense) and UAU CGU CCU CGU UGU AGG CTT (antisense). Six-well plates were transfected with siRNA and negative control (NC)-siRNA using transfection reagents for $24 \mathrm{~h}$ and then infected with DEV. Cell samples were collected to detect the effects of siRNA.

\section{Median tissue culture infective dosed $\left(\mathrm{TCID}_{50}\right)$}

DEF cells were cultured in covered 96-well plates and then infected with DEV virus diluted to $10^{-1}$ to $10^{-8}$. At $72 \mathrm{hpi}$, the cells were observed and pathological changes were recorded. Viral titers were determined according to the Reed-Muench method.

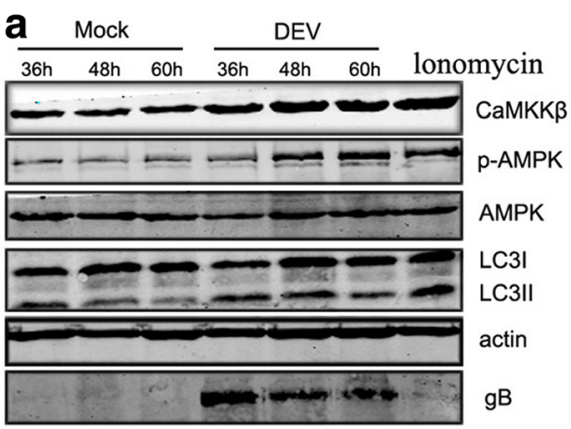

\section{b}
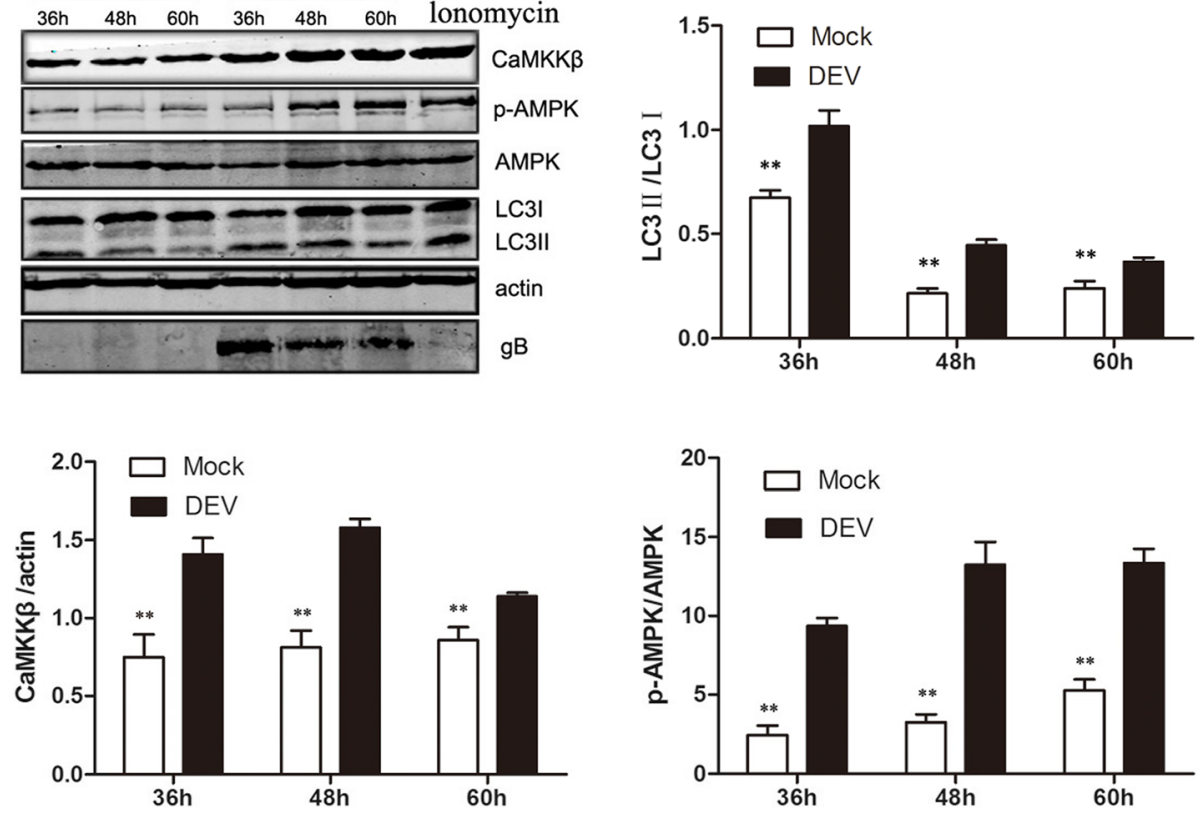

Fig. 1 DEV infection activated CaMKKB and its substrate AMPK, as well as increased the extent of LC3I transformation to LC3II. a DEF cells infected with DEV $(\mathrm{MOI}=1)$ or mock-infected cells were lysed and blotted with antibody against CaMKK $\beta$, p-AMPK, AMPK, LC3, and $\beta$-actin at the indicated times. Ionomycin treated cells as a postive control (b) The ratios of CaMKK $\beta / \beta$-actin. p-AMPKNAMPK, and LC3II/LC3I in DEF cells from three independent experiments, expressed as means \pm SD. ${ }^{*} p<0.05 ;{ }^{*} p<0.01$ 
Intracellular $\mathrm{Ca}^{2+}$ detection by flow cytometry

Cytosolic free $\mathrm{Ca}^{2+}$ ions were detected by using Fluo-3 AM. Fluo-3 AM itself is not combined with $\mathrm{Ca}^{2+}$ ions, but once dye is added to the cells, it can hybridize with Fluo-3 AM, and Fluo-3 AM will fluorescence upon binding to $\mathrm{Ca}^{2+}$. DEF cells were infected with DEV or treated with BAPTA-AM for the indicated times, then incubated with Fluo-3 AM in the dark at $37^{\circ} \mathrm{C}$ for $1 \mathrm{~h}$. Afterward, the cells were suspended in phosphate-buffered saline. To observe fluorescence, as an indicator of intracellular $\mathrm{Ca}^{2+}$ ions, the cells were monitored using a flow cytometer (BD FACSAria ${ }^{\mathrm{mw}}$; BD Biosciences, San Jose, CA, USA) at an excitation wavelength of $488 \mathrm{~nm}$.

\section{Statistical analysis}

All experimental results are expressed as the mean \pm standard deviation (SD) of three independent experiments. The Tukey's test was used for statistical analysis. A probability $(p)$ value of $<0.05$ was considered statistically significant.

\section{Results}

\section{CaMKK $\beta$-AMPK may be involved in DEV-induced} autophagy

Autophagy of DEV was induced via the AMPK/TSC2/ mTOR pathway in DEF cells. An investigation to determine whether any other underlying mechanism of AMPK activation was involved in autophagy induction showed that DEV infection significantly increased intracellular levels of CaMKK $\beta$ and its substrate molecule phosphorylated AMPK (p-AMPK) at 36, 48, and $60 \mathrm{hpi,} \mathrm{as} \mathrm{compared}$ to mock-infected cells. Microtubule-associated protein light chain (LC3) is an autophagy marker protein on the membranes of autophagosomes. When autophagosomes form, LC3I is phosphorylated by phosphatidyl ethanolamine (PE) to LC3II. LC3II remains on autophagosome membranes until fusion with lysosomes. Therefore, to some extent, LC3II expression measures the number of autophagosomes [22]. The expression level of LC3II also was significantly increased (Fig. 1a, b). This result indicated that CaMKK $\beta$-AMPK may be involved in DEV-induced autophagy.

\section{CaMKK $\beta$ is an upstream activator of AMPK involved in DEV-induced autophagy}

Next, we further verified the role of CaMKK $\beta$ in DEV-induced autophagy. Since CaMKK $\beta$ is activated in DEV-infected DEF cells, STO-609, a known CaMKK $\beta$ inhibitor, was used to assess changes in autophagy corresponding to the inhibition of CaMKK $\beta$. The results showed that activation of AMPK, LC3I transformation to LC3II were significantly lower in DEV-infected cells treated with STO-609, as compared to control cells. In addition, less $\mathrm{DEV}$ gB protein was observed in the drug-treated control cells (Fig. 2a).

To eliminate nonspecific effects of chemical drugs, siRNA was used to inhibit CaMKK $\beta$ expression. As shown in Fig. 2b, as compared to cells transfected with the NC-siRNA, DEF cells transfected with siRNA, expression levels of CaMKK $\beta$, activated AMPK, and LC3II were significantly reduced (Fig. 2b). The number of GFP-LC3
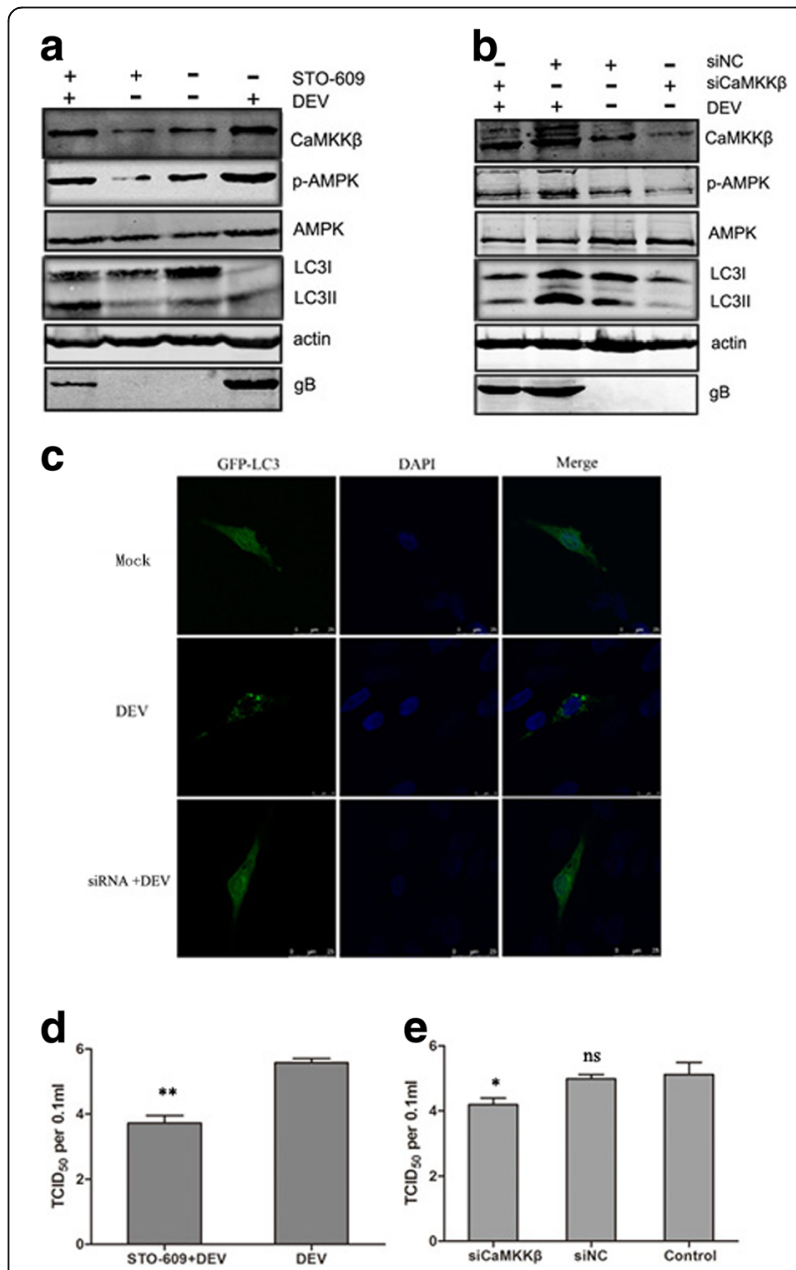

Fig. 2 Inhibition of CaMKKß by drug or siRNA downregulated the activity of AMPK and autophagy. a DEF cells were infected with DEV at a MOI of 1 in the presence or absence of STO-609 (10 $\mu \mathrm{M})$ for 36 hpi. Proteins extracted from cells treated with STO-609 and blotted with antibodies against CaMKK $\beta$, p-AMPK, AMPK, LC3, $\beta$-actin and gB. $\mathbf{b}$ DEF cells were infected with DEV $(\mathrm{MOI}=1)$ in the presence of siRNA targeting CaMKKß (siCaMKKß) for the indicated time points. Whole cell lysates at 36 hpi were subjected to western blot analysis. Representative images of immunoblots of target proteins extracted from cells treated with siCaMKK $\beta$ and blotted with antibodies against CaMKKB, p-AMPK, AMPK, LC3, and $\beta$-actin. c Representative confocal images of DEV-infected DEF cells with or without siCaMKK $\beta$ treatment. GFP-LC3 puncta were analyzed. d, e Viral titer $\left(T_{C I} D_{50}\right)$ at $48 \mathrm{hpi}$. All statistical data are reported as the mean \pm SEM of three independent experiments (ns, $p>0.05$; ${ }^{*} p<0.05$; and ${ }^{* *} p<0.01$ ) 
puncta decreased dramatically in siCaMKK $\beta$-treated DEV-infected cells, as compared to control cells (Fig. 2c).

Due to the decreased expression of viral proteins in response to CaMKK $\beta$ inhibition by chemical drugs or siRNA, we further checked whether inhibition of $\mathrm{CaMKK} \beta$ reduces viral replication. Viral titers were significantly decreased in DEV-infected DEF cells treated with STO-609 or siCaMKK $\beta$. The $\mathrm{TCID}_{50}$, as compared to control cells, at 48 hpi is shown in Fig. 2 d, e These results indicated that autophagy is related to CaMKK $\beta$ activation in DEV-infected DEF cells, and CaMKK $\beta$ is an upstream activator of AMPK involved in DEV-induced autophagy (Fig. 2d, e).

\section{DEV infection increased intracellular $\mathrm{Ca}^{2+}$ content to} activate CAMKK $\beta$

In order to further explore mechanisms involved in autophagy induction, upstream regulators were progressively explored. Some reports showed that an increase in cytosolic $\mathrm{Ca}^{2+}$ concentration $\left(\left[\mathrm{Ca}^{2+}\right]\right.$ cyto) promoted the autophagic process $[14,25]$. DEV-infected DEF cells were incubated with Fluo-3 AM. Then, at 36, 48 and 60 phi, intracellular $\mathrm{Ca}^{2+}$ was detected by flow cytometry, which showed that cytosolic $\mathrm{Ca}^{2+}$ in DEV-infected cells was higher than in mock-infected control cells, respectively (Fig. 3b). The result also showed that the increase in a

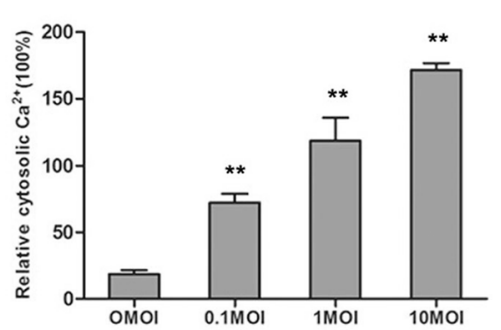

C

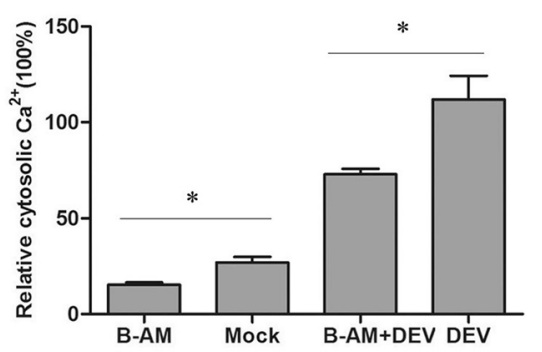

$\mathbf{e}$

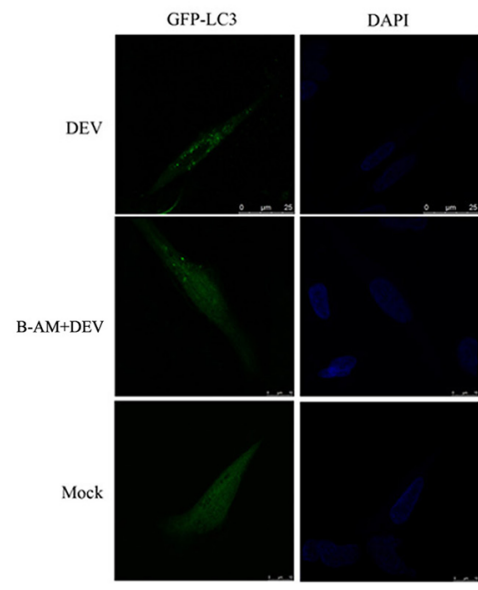

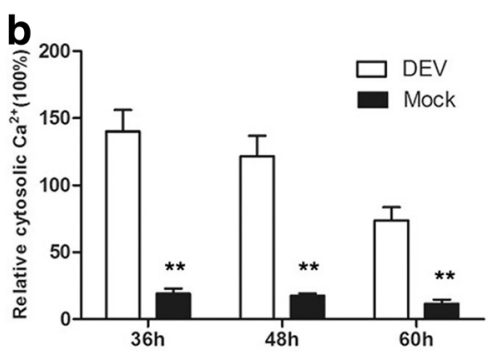

d
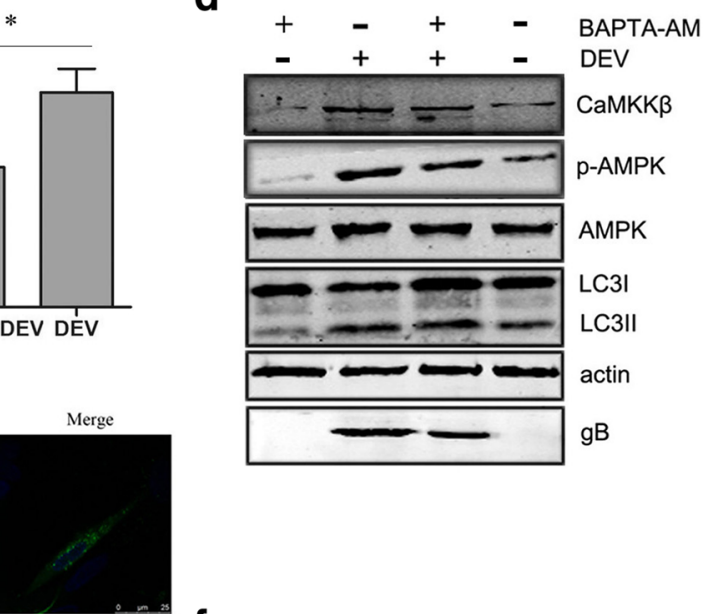

f

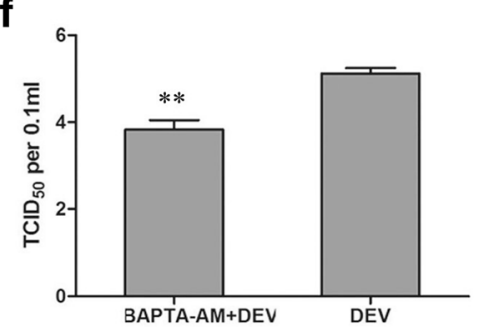

Fig. 3 DEV increased cytosolic calcium to activate CaMKK $\beta$ and AMPK. a DEF cells were infected with DEV at a MOI of 0.1-10. At 48 hpi,the cells cytosolic $\mathrm{Ca}^{2+}$ were measured based on Fluo 3-AM, a chemical $\mathrm{Ca}^{2+}$ indicator, relative to mock-infected cells. b DEF cells were infected with DEV at a MOI of 1. At 36, 48 and 60 hpi, the cells cytosolic $\mathrm{Ca}^{2+}$ were measured based on Fluo 3-AM relative to mock-infected cells. c DEV-infected cells treated with BAPTA-AM, the cells cytosolic $\mathrm{Ca}^{2+}$ were measured based on Fluo 3-AM relative to control cells. $\mathbf{d}$ Whole lysates of cells treated with BAPTA-AM or DEV collected at $36 \mathrm{hpi}$ were subjected to western blot analysis of CaMKK $\beta, \mathrm{p}-\mathrm{AMPK}, \mathrm{AMPK}, \mathrm{LC} 3, \beta$-actin and gB. e Representative confocal images of DEV-infected DEF cells with or without BAPTA-AM treatment. GFP-LC3 puncta were analyzed. $\mathbf{f}$ Viral titer $\left(\mathrm{TCID}_{50}\right)$ at $48 \mathrm{hpi}$. All statistical data are reported as the mean \pm SEM of three independent experiments $\left(\mathrm{ns}, p>0.05 ;{ }^{*} p<0.05\right.$; and $\left.{ }^{* *} p<0.01\right)$ 
cytosolic $\mathrm{Ca}^{2+}$ was dependent on the initial viral dose with a DEV multiplicity of infection (MOI) of $0.1-10$ at $48 \mathrm{hpi}$ (Fig. 3a).

BAPTA-AM is a well-established chelator of intracellular $\mathrm{Ca}^{2+}$ ions. Mock- or DEV-infected DEF cells were treated with $25 \mu \mathrm{m}$ BAPTA-AM for $30 \mathrm{~h}$, and intracellular $\mathrm{Ca}^{2+}$ was detected by flow cytometry. As expected, the results suggested that the addition of BAPTA-AM reduced intracellular $\mathrm{Ca}^{2+}$ levels (Fig. 3 c). Accordingly, CaMKK $\beta$ and AMPK activities were significantly decreased in BAPTA-AM-treated cells. After the addition of BAPTA-AM, LC3II expression and viral protein synthesis were significantly reduced (Fig. 3d). GFP-LC3 distribution was also observed by a confocal fluorescence microscopy as discrete puncta associated with autophagic vacuoles. The change in GFP-LC3 puncta number after drug treatment may response to changes in autophagic activity. As speculation, the number of GFP-LC3 puncta remarkable decreased in BAPTA-AM-treated DEV-infected cells, as compared to control cells, suggesting the inhibition of autophagy (Fig. 3e).

The expression of $\mathrm{gB}$ protein was reduced in BAPTA-AM-treated DEF cells, as compared with control cells. Consistent with the result, virus titers were significantly reduced in BAPTA-AM-treated DEF cells, as compared with control group cells. $\mathrm{TCID}_{50}$ assay was used to measure the DEV viral titers (Fig. 3f). Together, these data reflect that $\mathrm{Ca}^{2+}$ is necessary for the function of autophagy in DEV-infected DEF cells in a CaMKK $\beta$ and AMPK-dependent process.

\section{Cell viability unaffected by pharmacological treatment}

The siRNA targeting of endogenous genes or the drugs might have influenced cell viability and affected our results. The effects on cell viability of compounds used in this study were detected by WST-1 assays. Viability of treated cells was almost equal to mock cells, so the siRNA or pharmacological treatments did not affect DEF cell viability (Fig. 4).

\section{Discussion}

Autophagy is a tightly regulated and evolutionarily conserved intracellular process in which cells destroy and recycle cellular components in lysosomes. Much evidence indicates that virus-induced autophagy plays an important role in the viral life cycle and pathogenicity [26]. Many viruses have been reported to induce autophagy through multiple pathways [6,27]. The results of our previous study showed that DEV induced autophagic activation through impaired cellular energy metabolism via the AMPK-TSC2-MTOR signaling pathway. Two signaling molecules upstream from AMPK were involved cellular energy and $\mathrm{Ca}^{2+}$-mediated CAMKK $\beta$ activation. However, it remains unknown whether $\mathrm{Ca}^{2+}$-mediated

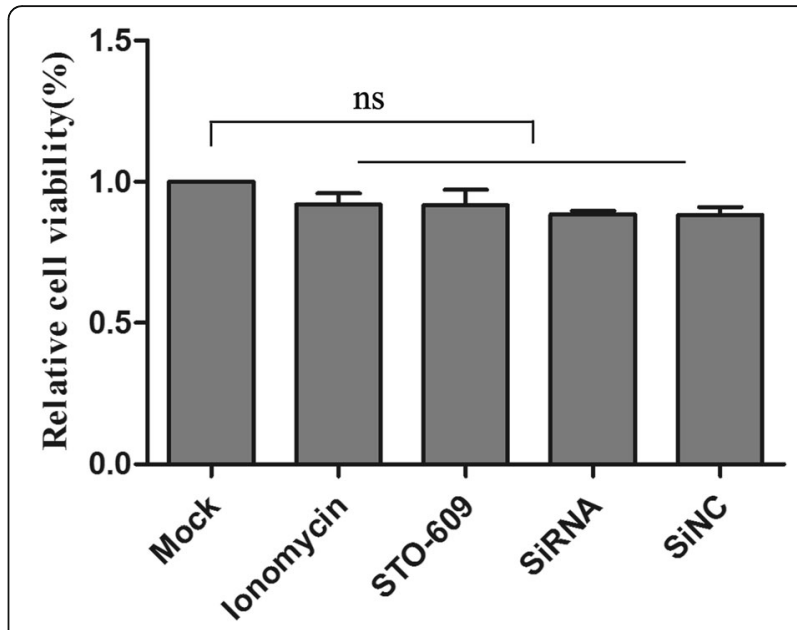

Fig. 4 SiRNA or pharmacology had no effect on cell viability. After cells were treated with Lonomycin, STO-609 and siRNA transfection for 48 h, cell viability was tested using WST kits as absorbent density at $450 \mathrm{~nm}$ expressed as relative cell viability (ratio of treated to blank cells). Bar represents $\pm S D$; ns indicates no significant difference, $p>0.05$

CaMKK $\beta$ can activate AMPK and a series of downstream signaling pathways during DEV-induced autophagy. The results of the present study suggested that DEV activates CAMKK $\beta$ and its substrate molecule APMK to trigger autophagy in DEF cells by increasing cytosolic $\mathrm{Ca}^{2+}$ concentrations.

Autophagy was first associated with intracellular $\mathrm{Ca}^{2+}$ regulation. Subsequent studies found that the removal of intracellular or extracellular $\mathrm{Ca}^{2+}$ ions inhibited autophagy [28]. Although the association between $\mathrm{Ca}^{2+}$ signaling and autophagy regulation has been reported, the underlying mechanisms remain unknown. $\mathrm{Ca}^{2+}$ ion control of autophagy is divided into two opposing view, that is, $\mathrm{Ca}^{2+}$ ions inhibit autophagy and promote autophagy. In this study, DEV infection induced an increase in intracellular $\mathrm{Ca}^{2+}$ and activated the formation of autophagosomes in DEF cells.

CaMKK $\beta$ is one of the most potent $\mathrm{Ca}^{2+}$-dependent protein kinases and is involved in a variety of signal transduction process. It is well known that AMPK (Thr172), CaMKI (Thr172), and CaMKIV (Thr200) can be directly phosphorylated by CaMKK $\beta$ to participate in autophagy [29]. In addition, activation of CaMKK $\beta$ is mainly dependent on conformational changes caused by the binding of $\mathrm{Ca}^{2+}$ and calmodulin. Therefore, the level of free $\mathrm{Ca}^{2+}$ in cytoplasm is essential for the activation of CaMKK $\beta$ [30].

$\mathrm{Ca}^{2+}$ and CaMKK $\beta$ are related with the activation of AMPK in T cells, hypothalamic neurous cells and endothelial cells,implying that $\mathrm{Ca}^{2+}$ metabolism may play an important role in AMPK-mTOR-regulated autophagy process [14]. Recent studies have found that in rotavirus-infected 
cells, CaMKK $\beta$ is activated by increased $\mathrm{Ca}^{2+}$ levels, further activating AMPK, which leads to subsequent autophagy [18]. Human cytomegalovirus infection can activate the CaMKK $\beta / A M P K$ pathway to promote cellular glucose metabolism and viral replication [31]. Here, although DEV infection indeed increased the cytoplasmic content of $\mathrm{Ca}^{2+}$ ions, the underlying mechanism is not clear. However, it has been speculated that the virus may encode one or more proteins that change biomembrane permeability to $\mathrm{Ca}^{2+}$, causing an increase in $\left[\mathrm{Ca}^{2+}\right]$ cyto originating from ER or Golgi $\left[\mathrm{Ca}^{2+}\right]$ stores, or the extracellular environment $[18,32]$. The results of our previous study confirmed that the ER stress response is involved in DEV-induced autophagy, suggesting that there might be some links between ER stress and elevated $\left[\mathrm{Ca}^{2+}\right]$ cyto.

\section{Conclusions}

The results of the present study demonstrated that CaMKK $\beta$ is an upstream regulator of AMPK during DEV infection, which contributes to autophagy induction. Activation of CaMKK $\beta$ results from an increase in cytosolic $\mathrm{Ca}^{2+}$ content. This research lays a foundation for DEV pathogenic mechanism research and provides further insight into DEV-host cell interactions.

\begin{abstract}
Abbreviations
AMPK: Adenosine 5'-monophosphate-activated protein kinase; BAPTAAM: 1,2-Bis (2-aminophenoxy) ethane-N, N, N', N-tetraacetic acid; DEF: Duck embryo fibroblast; DEV: Duck enteritis virus; ER: Endoplasmic reticulum
\end{abstract}

\section{Funding}

This work was supported by the Natural Science Foundation of Heilongjiang Province (QC2018033), the Key Program of Natural Science Foundation of Heilongjiang Province (ZD2016006) and Central Public-interest Scientific Institution Basal Fund (NO.1610302017013; NO.1610302018013).

\section{Author contributions}

HC, LZ and HY conceived and designed the study. HY and SL performed the experiments and analyzed the data. YW and $\mathrm{HH}$ drew the graphs. $\mathrm{HY}$ and LZ wrote the paper. All authors read and approved the final manuscript.

\section{Availability of data and materials}

The datasets analyzed during the current study available from the corresponding author on reasonable request.

\section{Ethics approval and consent to participate}

The study was approved by Harbin Veterinary Research Institute and performed in accordance with animal ethics guidelines and approved protocols. The animal Ethics Committee approval number is HeilongjiangSYXK-2006-032.

\section{Consent for publication}

Not applicable.

\section{Competing interests}

The authors declare that there is no conflict of interest regarding the publication of this article.

\section{Publisher's Note}

Springer Nature remains neutral with regard to jurisdictional claims in published maps and institutional affiliations.

\section{Author details}

${ }^{1}$ State Key Laboratory of Veterinary Biotechnology, Heilongjiang Provincial Key Laboratory of Laboratory Animal and Comparative Medicine, Harbin Veterinary Research Institute, the Chinese Academy of Agriculture Sciences, 678 Haping Road, Harbin 150069, People's Republic of China. ${ }^{2}$ College of Life Science and Agriculture Forestry, Qiqihar University, Qiqihar 161006, China. ${ }^{3}$ Heilongjiang Provincial Key Laboratory of Resistance Gene Engineering and Protection of Biodiversity in Cold Areas, Qiqihar, Heilongjiang 161006, China.

Received: 23 April 2018 Accepted: 18 July 2018

Published online: 06 August 2018

\section{References}

1. Wang G, Qu Y, Wang F, Hu D, Liu L, Li N, Yue R, Li C, Liu S. The comprehensive diagnosis and prevention of duck plague in Northwest Shandong province of China. Poult Sci. 2013;92:2892-8.

2. Hu Y, Zhou H, Yu Z, Chen H, Jin M. Characterization of the genes encoding complete US10, SORF3, and US2 proteins from duck enteritis virus. Virus Genes. 2009;38:295-301.

3. Stolz A, Ernst A, Dikic I. Cargo recognition and trafficking in selective autophagy. Nat Cell Biol. 2014;16:495-501.

4. Molino D, Zemirli N, Codogno P, Morel E. The journey of the autophagosome through mammalian cell organelles and membranes. J Mol Biol. 2017:429:497-514.

5. Deretic V, Levine B. Autophagy, immunity, and microbial adaptations. Cell Host Microbe. 2009:5:527-49.

6. Jackson WT. Viruses and the autophagy pathway. Virology. 2015;479480:450-6.

7. Chiramel Al, Brady NR, Bartenschlager R. Divergent roles of autophagy in virus infection. Cells. 2013:2:83-104.

8. Wang CW, Klionsky DJ. The molecular mechanism of autophagy. Mol Med. 2003;9:65-76.

9. Berridge MJ, Lipp P, Bootman MD. The versatility and universality of calcium signalling. Nat Rev Mol Cell Biol. 2000;1:11-21.

10. Berridge MJ, Bootman MD, Roderick HL. Calcium signalling: dynamics, homeostasis and remodelling. Nat Rev Mol Cell Biol. 2003;4:517-29.

11. Ghislat G, Knecht E. Ca(2)(+)-sensor proteins in the autophagic and endocytic traffic. Curr Protein Pept Sci. 2013;14:97-110.

12. Decuypere JP, Bultynck G, Parys JB. A dual role for ca(2+) in autophagy regulation. Cell Calcium. 2011;50:242-50.

13. Vingtdeux V, Giliberto $L$, Zhao $H$, Chandakkar $P$, Wu Q, Simon JE, Janle EM, Lobo J, Ferruzzi MG, Davies P, Marambaud P. AMP-activated protein kinase signaling activation by resveratrol modulates amyloid-beta peptide metabolism. J Biol Chem. 2010;285:9100-13.

14. Hoyer-Hansen M, Bastholm L, Szyniarowski P, Campanella M, Szabadkai G, Farkas T, Bianchi K, Fehrenbacher N, Elling F, Rizzuto R, et al. Control of macroautophagy by calcium, calmodulin-dependent kinase kinase-beta, and Bcl-2. Mol Cell. 2007;25:193-205.

15. Zhou Y, Frey TK, Yang JJ. Viral calciomics: interplays between $\mathrm{Ca} 2+$ and virus. Cell Calcium. 2009:46:1-17.

16. Fung TS, Torres J, Liu DX. The emerging roles of Viroporins in ER stress response and autophagy induction during virus infection. Viruses. 2015;7: 2834-57.

17. LV Y, Dai L, Han H, Zhang S. PCV2 induces apoptosis and modulates calcium homeostasis in piglet lymphocytes in vitro. Res Vet Sci. 2012;93: 1525-30.

18. Crawford SE, Hyser JM, Utama B, Estes MK. Autophagy hijacked through viroporin-activated calcium/calmodulin-dependent kinase kinase-beta signaling is required for rotavirus replication. Proc Natl Acad Sci U S A. 2012; 109:E3405-13.

19. Geng X, Harry BL, Zhou Q, Skeen-Gaar RR, Ge X, Lee ES, Mitani S, Xue D. Hepatitis $B$ virus $X$ protein targets the $B C l-2$ protein CED-9 to induce intracellular Ca2+ increase and cell death in Caenorhabditis elegans. Proc Natl Acad Sci U S A. 2012;109:18465-70.

20. Cheshenko N, Del Rosario B, Woda C, Marcellino D, Satlin LM, Herold BC Herpes simplex virus triggers activation of calcium-signaling pathways. J Cell Biol. 2003;163:283-93.

21. Lv S, Xu QY, Sun EC, Zhang JK, Wu DL. Dissection and integration of the autophagy signaling network initiated by bluetongue virus infection: crucial candidates ERK1/2. Akt and AMPK Sci Rep. 2016;6:23130. 
22. Yin HC, Zhao LL, Li SQ, Niu YJ, Jiang XJ, Xu LJ, Lu TF, Han LX, Liu SW, Chen HY. Autophagy activated by duck enteritis virus infection positively affects its replication. J Gen Virol. 2017;98:486-95.

23. Yin $H$, Zhao L, Li S, Xu L, Wang Y, Chen H. Impaired cellular energy metabolism contributes to duck-enteritis-virus-induced autophagy via the AMPK-TSC2-MTOR signaling pathway. Front Cell Infect Microbiol. 2017;7:423.

24. Jacolot S, Ferec C, Mura C. Iron responses in hepatic, intestinal and macrophage/monocyte cell lines under different culture conditions. Blood Cells Mol Dis. 2008;41:100-8.

25. Gao W, Ding WX, Stolz DB, Yin XM. Induction of macroautophagy by exogenously introduced calcium. Autophagy. 2008;4:754-61.

26. Chen N, Karantza V. Autophagy as a therapeutic target in cancer. Cancer Biol Ther. 2011;11:157-68.

27. Dreux M, Chisari FV. Viruses and the autophagy machinery. Cell Cycle. 2010; 9:1295-307.

28. Gordon PB, Holen I, Fosse M, Rotnes JS, Seglen PO. Dependence of hepatocytic autophagy on intracellularly sequestered calcium. J Biol Chem. 1993;268:26107-12.

29. Pfisterer SG, Mauthe M, Codogno P, Proikas-Cezanne T. Ca2+/calmodulindependent kinase (CaMK) signaling via CaMKI and AMP-activated protein kinase contributes to the regulation of WIPI-1 at the onset of autophagy. Mol Pharmacol. 2011:80:1066-75.

30. Hassan H, Tian X, Inoue K, Chai N, Liu C, Soda K, Moeckel G, Tufro A, Lee AH, Somlo $S$, et al. Essential role of X-box binding Protein-1 during endoplasmic reticulum stress in podocytes. J Am Soc Nephrol. 2016;27:1055-65.

31. McArdle J, Schafer XL, Munger J. Inhibition of calmodulin-dependent kinase kinase blocks human cytomegalovirus-induced glycolytic activation and severely attenuates production of viral progeny. J Virol. 2011;85:705-14.

32. Kim J, Kundu M, Viollet B, Guan KL. AMPK and mTOR regulate autophagy through direct phosphorylation of Ulk1. Nat Cell Biol. 2011;13:132-U171.

Ready to submit your research? Choose BMC and benefit from:

- fast, convenient online submission

- thorough peer review by experienced researchers in your field

- rapid publication on acceptance

- support for research data, including large and complex data types

- gold Open Access which fosters wider collaboration and increased citations

- maximum visibility for your research: over $100 \mathrm{M}$ website views per year

At $\mathrm{BMC}$, research is always in progress.

Learn more biomedcentral.com/submissions 